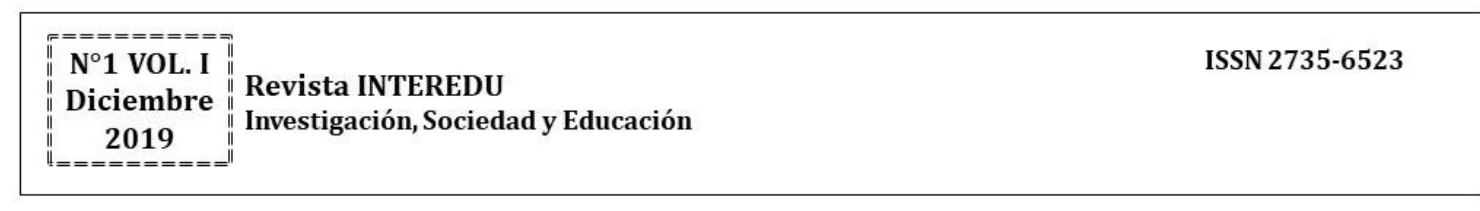

https://doi.org/10.32735/S2735-65232019000182

95--119

\title{
ANÁLISIS COMPARATIVO DE LAS TAXONOMÍAS EN USO PARA LA PLANIFICACIÓN DIDÁCTICA DE LENGUAJE Y LITERATURA EN LA ENSEÑANZA MEDIA
}

Comparative analysis of the taxonomies in use for didactic planning of Language and Literature in Secondary Education

\author{
CRISTIAN IGNACIO DOMÍNGUEZ R. \\ Colegio Creación, Osorno \\ cristianignaciodr@gmail.com \\ JAVIER ROSAS MONTIEL \\ Osorno College \\ javierrosasmontiel@hotmail.com
}

\section{RESUMEN}

El presente trabajo es resultado de un estudio y análisis comparativo entre las taxonomías de Benjamin Bloom, SOLO de Biggs, Lorin Anderson, L. Dee Fink y Robert J. Marzano. En este análisis se evidencian elementos comunes y diferenciadores asociados y relacionados a los procesos de enseñanza aprendizaje. Se consideró la incorporación de contenidos y actividades de aprendizaje del sector de Lenguaje y Comunicación para la extrapolación de las taxonomías. Con los elementos expuestos, al final del texto se presenta una propuesta que permite evidenciar la adaptación y uso de distintos ordenamientos en un solo proceso o unidad, logrando así robustecer los procesos en función del aprendizaje del alumno y la práctica docente.

Palabras clave: Planificación didáctica; práctica docente; proceso de enseñanza aprendizaje; taxonomías.

\section{ABSTRACT}

This work is the result of a comparative study and analysis between the taxonomies of Benjamin Bloom, SOLO de Biggs, Lorin Anderson, L. Dee Fink and Robert J. Marzano. This analysis shows common elements and differentiators, associated and related to teaching-learning processes. The incorporation of both, content and learning activities, from the subject "Lenguaje y Comunicación" were considered for the extrapolation of taxonomies. At the end of the text is presented a proposal that allows to show the adaptation and use of different systems in a single 
process or unity, thus managing to strengthen both, the quality of students' learning processes and the teaching practice.

Key words: Didactic planning; teaching practice; teaching and learning process; taxonomies.

\section{ANTECEDENTES, JUSTIFICACIÓN Y FORMULACIÓN DEL PROBLEMA}

La estructura y planificación de una clase es el foco de atención al momento de plantear los contenidos en un proceso de enseñanza aprendizaje. Pensar cómo ordenar y planificar con base a planes y programas de estudio, disponer del tiempo necesario en función de las necesidades de los alumnos y encausar los procesos por medio de distintas estrategias y metodologías, forman parte del cotidiano de la formación del docente (Bitar, 2011). Es por ello que, para poder fortalecer esta tarea, nos hemos dispuesto a realizar un análisis comparativo de diferentes taxonomías como elementos fundamentales para el refuerzo y evaluación del conocimiento y habilidades de los estudiantes. En este estudio taxonómico se consideraron las taxonomías de: Benjamin Bloom, Solo de Biggs, Lorin Anderson, L. Dee Fink y Robert J. Marzano.

El objetivo que nos llevó a investigar este fenómeno fue la necesidad de tener bases concretas y herramientas para transmitir conocimientos que sean significativos para los estudiantes de Enseñanza Media en el ámbito de la enseñanza del Lenguaje y la Comunicación y que perduren en la vida de los estudiantes. Además, orientar los procesos de enseñanza aprendizaje en sus distintas etapas.

Algo clave para llevar a cabo este objetivo está intrínsecamente ligado a la formación de pregrado que el docente recibe desde la educación universitaria. Lo anterior se funda en el conocimiento de procedimientos que son de gran relevancia para formar capacidades de trabajo en los docentes en formación.

Debemos tener en cuenta que dentro un establecimiento educacional se imparte una variedad de materias y/o asignatura, donde cada una necesita de un método distinto para que los estudiantes logren asimilar lo que se está entregando. Es por ello que para el docente es de vital importancia tener una clara idea de cómo va a ordenar su actividad y cuáles van a ser los pasos a seguir para lograr una adquisición de conocimientos de manera significativa, además de posibilitar ordenar sus objetivos con base a lo que propondrá como meta el docente.

Consideramos relevante el uso de taxonomías para la estructura, organización y planificación del proceso de enseñanza aprendizaje (E-A) en el aula, ya que mediante estas se permite encausar de forma más certera cada etapa de una clase en su inicio, desarrollo y cierre. Por otro lado, desplegar los contenidos considerando las realidades grupales 96 | INTEREDU № 1 VOL. I (DiCIEMBRE 2019) PÁGS. 95-119. ISSN 2735-6523 
detectadas en cada curso, permitiendo niveles de evaluación según las diferentes formas de aprendizajes que están relacionadas con los objetivos tanto del profesor como del programa que debe seguir.

En cuanto a los niveles de las taxonomías tienden a poseer diferentes finalidades, ya que cada una de ella tiene su fundamento conceptual, mediante los cuales los profesores y profesoras pueden organizar y aplicar estrategias que incorporen estos niveles, logrando así una estructura planificada, reforzada y robusta de su clase o unidad en el proceso de enseñanza aprendizaje en general, elementos de conocimiento incorporados desde la formación inicial (Pavié, 2014).

\section{OBjETIVOS}

Como principales objetivos de la investigación se pueden identificar los que a continuación se detallan, a saber:

\subsection{OBJETIVO GENERAL:}

El estudio tiene como objetivo general comprender y aplicar taxonomías específicas en las distintas etapas de los procesos de enseñanza aprendizaje en la práctica habitual docente, para lograr estructuras ordenadas, planificadas y adecuadas a los distintos contextos educativos de una clase o unidad y curso.

\subsection{Objetivos EsPecíficos:}

a) Comparar las distintas taxonomías propuestas por cinco autores, los cuales son: Benjamín Bloom, Anderson, Solo, Marzano y Fink, llevándolas al área de Lenguaje y Comunicación.

b) Incorporar objetivos y actividades de aprendizaje dados en Lenguaje y Comunicación a cada nivel taxonómico de los autores propuestos como elementos ejemplificadores y relacionadores.

c) Proponer un modelo didáctico de uso metodológico de las taxonomías.

\section{Metodología de tRABAjo}

Este estudio es de carácter cualitativo con un método de análisis documental (Vélez, 2009). Se considera información preestablecida de cinco taxonomías, que han sido utilizadas en diferentes contextos educativos estas son: la taxonomía de Bloom, SOLO, Anderson, Fink y Marzano y sus niveles. Usando las taxonomías los docentes tienen la seguridad de evaluar a sus estudiantes en diferentes formas de aprendizajes que están relacionados con los 
objetivos tanto del profesor como del programa que tiene que seguir. Los niveles de las taxonomías tienden a poseer diferentes finalidades que el estudiante deberá desarrollar de acuerdo a lo enseñado por el docente. Así, las taxonomías desarrollan no solo el conocimiento, sino que también la forma en cómo los estudiantes refuerzan los contenidos. Comenzando primero por conocer los conceptos hasta llegar a su posterior aplicación en situaciones determinadas. Todo lo estudiado y aprendido durante las horas de clases parte de una estructura y organización, siendo esta la principal forma o el cómo este conocimiento será enseñado.

Se incorpora el área de Lenguaje y Comunicación para profundizar y ejemplificar utilizando el libro de Lenguaje y Comunicación (SM, 2020), Tercero Medio, Unidad 1, "Héroes y Villanos", lección 3 de textos informativos. El análisis comparativo es presentado por medio de tablas que contienen los distintos niveles de cada taxonomía separadas en:

Primera categoría: Presenta los propósitos del ordenamiento para realizar el proceso de enseñanza y aprendizaje de manera eficiente. Esto ayuda a entender por qué cada autor ha

presentado una postura distinta y qué factores fueron cruciales para la elaboración de su idea, considerando concepto, elementos comunes y elementos diferenciadores.

Segunda categoría: Organización-planificación, basada en los objetivos señalados en el currículum de Lenguaje y Comunicación y aplicable a la unidad de textos informativos. Presenta la forma como los autores han ordenado las taxonomías, lo cual está conectado de manera intrínseca con cómo el docente debe planificar su clase y organizar su material de trabajo. Para finalizar, se genera una propuesta taxonómica que aborda niveles y elementos específicos de cada autor estudiado con categorías que se adscriben mejor a la educación contemporánea del contexto educativo nacional.

\section{FUNDAMENTACIÓN TEÓRICA}

\subsection{BASADA EN EL MODELO TAXONÓMICO DE BENJAMIN BLOOM}

Es una taxonomía que se preocupa por la imprecisión de objetivos educacionales por parte de los docentes y expertos en currículum. Por tal motivo, se ideó una propuesta que diera respuesta y solución a las dos interrogantes: ¿cómo se aprende? y ¿cómo se evalúan los aprendizajes? Dicha taxonomía se clasifica en tres dominios en los cuales el estudiante debe avanzar y demostrar su progreso:

- Dominio cognitivo: Está relacionado con la evolución que tiene el alumno mediante la adquisición de conocimientos por medio de la información recibida en diferentes contextos. La cognición implica elementos tales como:

98 | INTEREDU № 1 VOL. I (DiCIEMBRE 2019) PÁGS. 95-119. ISSN 2735-6523 
el pensamiento, el lenguaje, la percepción, entre otros; los cuales ayudan a desarrollar la intelectualidad del individuo.

- Dominio afectivo: Apela a las emociones de los estudiantes, que tienden a reaccionar frente a distintas situaciones que se presentan en el contexto educativo. La empatía en este dominio es fundamental para reforzar el crecimiento en la madurez emocional e intelectual de los individuos y su percepción frente al espacio que los rodea, adquiriendo conocimientos -en el dominio cognitivo- que le sean de utilidad en situaciones adversas.

- Dominio psicomotor: Se refiere al propósito más empírico en términos educativos. Lo que busca es dar al funcionamiento común del desarrollo de la enseñanza una perspectiva didáctica de la disciplina. De este modo, permite que los alumnos puedan aprender realizando trabajos educativos que fomenten y aprovechen las habilidades que cada estudiante posee.

\subsection{MOdELO TAXONÓMICO DE SOLO DE J. BigGS}

Se establece aquí una relación entre la teoría psicológica y la práctica educativa. Se basa en la importancia de analizar y reflexionar sobre los resultados que se podían observar en los aprendizajes de complejidad cognitiva ascendente. La utilidad de esta taxonomía se encuentra en que sirve tanto para el docente, así como para los alumnos. Lo anterior gana relevancia, ya que al docente le permite conocer el nivel de pensamientos de los estudiantes y trabajar de mejor forma con ellos, y a los estudiantes les ayuda a aprender y lograr forjar un aprendizaje profundo. La taxonomía SOLO se basa en la importancia de prestar atención a los resultados observables del aprendizaje que los sitúa en niveles de complejidad cognitiva ascendente. Es decir, mientras más conocimiento adquiera el estudiante su nivel cognitivo irá aumentando.

\subsection{MODELO TAXONÓMICO DE FINK}

La taxonomía de objetivos de aprendizaje de Fink está más centrada en el alumno que en el contenido. Esta taxonomía no es jerárquica, es decir, que todos los tipos de aprendizaje son necesarios y trabajan juntos para crear una persona que se adapte al contexto. La Taxonomía de Fink incluye aspectos de los tres dominios de Bloom (cognitivo, afectivo y psicomotor), así como los aspectos meta-cognitivos. Esta taxonomía consta de seis tipos de aprendizajes los cuales tienen el propósito de formar personas capaces de efectuar variados tipos de actividades. 


\subsection{MODELO TAXONÓMICO DE MARZANO Y KENDALL}

Marzano y Kendall identificaron tres áreas centrales para las reformas que buscan la mejora escolar: fomentar y mantener estrategias de enseñanza en todo el sistema, proporcionar retroalimentación efectiva a los estudiantes y construir un vocabulario académico fuerte para los estudiantes (Rodríguez Puerta, s/f).

La taxonomía creada por Marzano y Kendall se orienta a un ámbito más práctico y por tanto sirve para el diseño de situaciones de aprendizaje específicas que pretenden aumentar el nivel de conocimiento del aprendiz de forma gradual. Marzano y Kendall tuvieron en cuenta el hecho de que en el proceso de aprendizaje no todo lo que se aprende o lo que influye sobre este proceso es visible; aspectos subjetivos importantes como la motivación, la memoria, las emociones y la meta-cognición del individuo son esenciales.

La taxonomía de Marzano y Kendall está formada principalmente por dos dimensiones que interactúan entre sí: los dominios de conocimiento y los niveles de procesamiento.

Dominios de conocimiento: Se trata del tipo de aprendizajes que un alumno puede llevar a cabo. Los conocimientos que podemos aprender son principalmente de tres tipos:

- Información: Se adquieren conocimientos.

- Procedimientos mentales: Son formas de pensar que requieren seguir unos pasos para alcanzar un objetivo.

- Procedimientos psicomotores: Son todos los conocimientos relacionados con el uso del cuerpo y las habilidades físicas.

Niveles de procesamiento: Se trata del nivel de profundidad con la que el alumno adquiere un conocimiento nuevo. Aunque está dividida en los niveles cognitivo, metacognitivo, e interno, en la práctica se suelen dividir en seis subniveles.

\section{CATEGORÍAS Y ANÁLISIS COMPARATIVOS}

\subsection{PRIMERA CATEGORÍA}

Cada taxonomía presenta una estructura y orden diferente. De estas divisiones analizaremos todas ellas para llevar a cabo una comparación sistemática que pondrá en evidencia las similitudes y diferencias que existan entre las categorías consideradas con el fin de dar cuenta de los objetivos específicos de esta investigación, lo que se desglosa en las tablas que a continuación se presentan. 
Tabla 1. Comparación primer nivel taxonómico.

\begin{tabular}{|c|c|c|c|c|c|}
\hline Autores & $\begin{array}{l}\text { Bloom } \\
(1956)\end{array}$ & $\begin{array}{l}\text { SOLO } \\
(1982)\end{array}$ & $\begin{array}{l}\text { Anderson } \\
(2001)\end{array}$ & $\begin{array}{l}\text { Fink } \\
(2003)\end{array}$ & $\begin{array}{l}\text { Marzano } \\
(2007)\end{array}$ \\
\hline Primer nivel & Conocimiento & Preestructural. & Recordar. & $\begin{array}{l}\text { Conocimiento } \\
\text { fundacional. }\end{array}$ & Recuperación. \\
\hline \multicolumn{6}{|c|}{ Conceptos y elementos comunes } \\
\hline Emisor receptor & \multicolumn{5}{|c|}{$\begin{array}{l}\text { En este nivel es indispensable la presencia de un emisor, en este caso el profesor, } \\
\text { que se desempeña como un medio o canal para educar y enseñar información } \\
\text { que es relevante en los receptores, que vienen siendo los estudiantes. }\end{array}$} \\
\hline Información & \multicolumn{5}{|c|}{$\begin{array}{l}\text { En cada taxonomía encontramos una entrega de contenido por parte del docente } \\
\text { a los alumnos. }\end{array}$} \\
\hline $\begin{array}{l}\text { Habilidad } \\
\text { cognitiva }\end{array}$ & \multicolumn{5}{|c|}{$\begin{array}{l}\text { La habilidad cognitiva de recordar la información entregada es reforzada } \\
\text { constantemente y utilizada por el profesor para traer a la mente conocimientos } \\
\text { enseñados anteriormente. }\end{array}$} \\
\hline Aprendizaje & \multicolumn{5}{|c|}{$\begin{array}{l}\text { Se aprende algo nuevo en base a aciertos y errores mediante la participación en } \\
\text { el proceso de enseñanza. }\end{array}$} \\
\hline \multicolumn{6}{|c|}{ Elementos diferenciadores } \\
\hline \multicolumn{2}{|c|}{$\begin{array}{l}\text { Bloom } \\
(1956)\end{array}$} & $\begin{array}{l}\text { SOLO } \\
(1982)\end{array}$ & $\begin{array}{l}\text { Anderson } \\
(2001)\end{array}$ & $\begin{array}{l}\text { Fink } \\
(2003)\end{array}$ & $\begin{array}{c}\text { Marzano } \\
\text { (2007) }\end{array}$ \\
\hline \multicolumn{2}{|c|}{$\begin{array}{l}\text { Busca recordar información que } \\
\text { permita dar paso a la } \\
\text { memorización de contenidos } \\
\text { específicos, los cuales son } \\
\text { guiados continuamente a través } \\
\text { de la observación. }\end{array}$} & $\begin{array}{l}\text { Busca reconocer } \\
\text { información } \\
\text { que está en la } \\
\text { memoria de los } \\
\text { alumnos. Sin } \\
\text { embargo, } \\
\text { presenta un } \\
\text { modelo } \\
\text { abstracto en } \\
\text { comparación } \\
\text { con las demás }\end{array}$ & $\begin{array}{l}\text { Se recuerda } \\
\text { y analiza } \\
\text { informació } \\
\text { n mediante } \\
\text { conceptos } \\
\text { básicos. }\end{array}$ & $\begin{array}{l}\text { Se comprende } \\
\text { información a } \\
\text { través de } \\
\text { diferentes } \\
\text { ideas que cada } \\
\text { estudiante } \\
\text { haya } \\
\text { aprendido o } \\
\text { conocido con } \\
\text { anterioridad. }\end{array}$ & $\begin{array}{l}\text { Tiene un } \\
\text { proceso de } \\
\text { aprendizaje } \\
\text { basado en la } \\
\text { forma en que } \\
\text { los contenidos } \\
\text { son } \\
\text { enseñados. }\end{array}$ \\
\hline
\end{tabular}




\begin{tabular}{|l|l|l|l|l|}
\hline & $\begin{array}{l}\text { taxonomías, ya } \\
\text { que no presenta } \\
\text { la forma en que }\end{array}$ & & & \\
plantea la & & & \\
entrega r y & & & \\
adquisición de & & & \\
aprendizajes es & & & \\
distinta. & & & \\
\hline
\end{tabular}

Fuente: Elaboración propia.

Tabla 2. Comparación segundo nivel taxonómico.

\begin{tabular}{|c|c|c|c|c|c|}
\hline Autores & $\begin{array}{l}\text { Bloom } \\
(1956)\end{array}$ & $\begin{array}{l}\text { SOLO } \\
(1982)\end{array}$ & $\begin{array}{l}\text { Anderson } \\
(2001)\end{array}$ & $\begin{array}{l}\text { Fink } \\
(2003)\end{array}$ & $\begin{array}{l}\text { Marzano } \\
(2007)\end{array}$ \\
\hline Segundo nivel & Comprensión. & Uniestructural. & Comprender. & Aplicación. & Comprensión. \\
\hline \multicolumn{6}{|c|}{ Conceptos y elementos comunes } \\
\hline Material & \multicolumn{5}{|c|}{$\begin{array}{l}\text { Corresponde al material educativo que es utilizado por los estudiantes para la } \\
\text { comprensión de ideas y elaboración de respuestas. }\end{array}$} \\
\hline Selección & \multicolumn{5}{|c|}{$\begin{array}{l}\text { Acción que el alumno realiza para escoger información específica en relación al } \\
\text { contenido. }\end{array}$} \\
\hline Construcción & \multicolumn{5}{|c|}{$\begin{array}{l}\text { A través del contenido desarrollado y comprendido los estudiantes son capaces de } \\
\text { construir una respuesta objetiva. }\end{array}$} \\
\hline \multicolumn{6}{|c|}{ Elementos diferenciadores } \\
\hline \multicolumn{2}{|c|}{$\begin{array}{l}\text { Bloom } \\
(1956)\end{array}$} & $\begin{array}{l}\text { SOLO } \\
(1982)\end{array}$ & $\begin{array}{l}\text { Anderson } \\
(2001)\end{array}$ & $\begin{array}{l}\text { Fink } \\
(2003)\end{array}$ & $\begin{array}{c}\text { Marzano } \\
(2007)\end{array}$ \\
\hline \multicolumn{2}{|c|}{$\begin{array}{l}\text { Busca que el alumno sea } \\
\text { capaz de adquirir un } \\
\text { aprendizaje significativo con } \\
\text { el objetivo de poder llevarlo a } \\
\text { otros contextos. }\end{array}$} & $\begin{array}{l}\text { La dificultad y } \\
\text { exigencia } \\
\text { solicitada por el } \\
\text { docente solo se } \\
\text { limita a la lectura }\end{array}$ & $\begin{array}{l}\text { El objetivo es } \\
\text { que los } \\
\text { estudiantes } \\
\text { le den un } \\
\text { significado a } \\
\text { la }\end{array}$ & $\begin{array}{l}\text { A través del } \\
\text { traspaso de } \\
\text { información } \\
\text { el alumno } \\
\text { es capaz de } \\
\text { utilizarla }\end{array}$ & $\begin{array}{l}\text { El conocimiento } \\
\text { previo que cada } \\
\text { estudiante posee } \\
\text { de manera } \\
\text { individual es } \\
\text { fundamental }\end{array}$ \\
\hline
\end{tabular}

102 | INTEREDU № 1 VOL. I(DiCIEMBRe 2019) PÁGs. 95-119. ISSN 2735-6523 


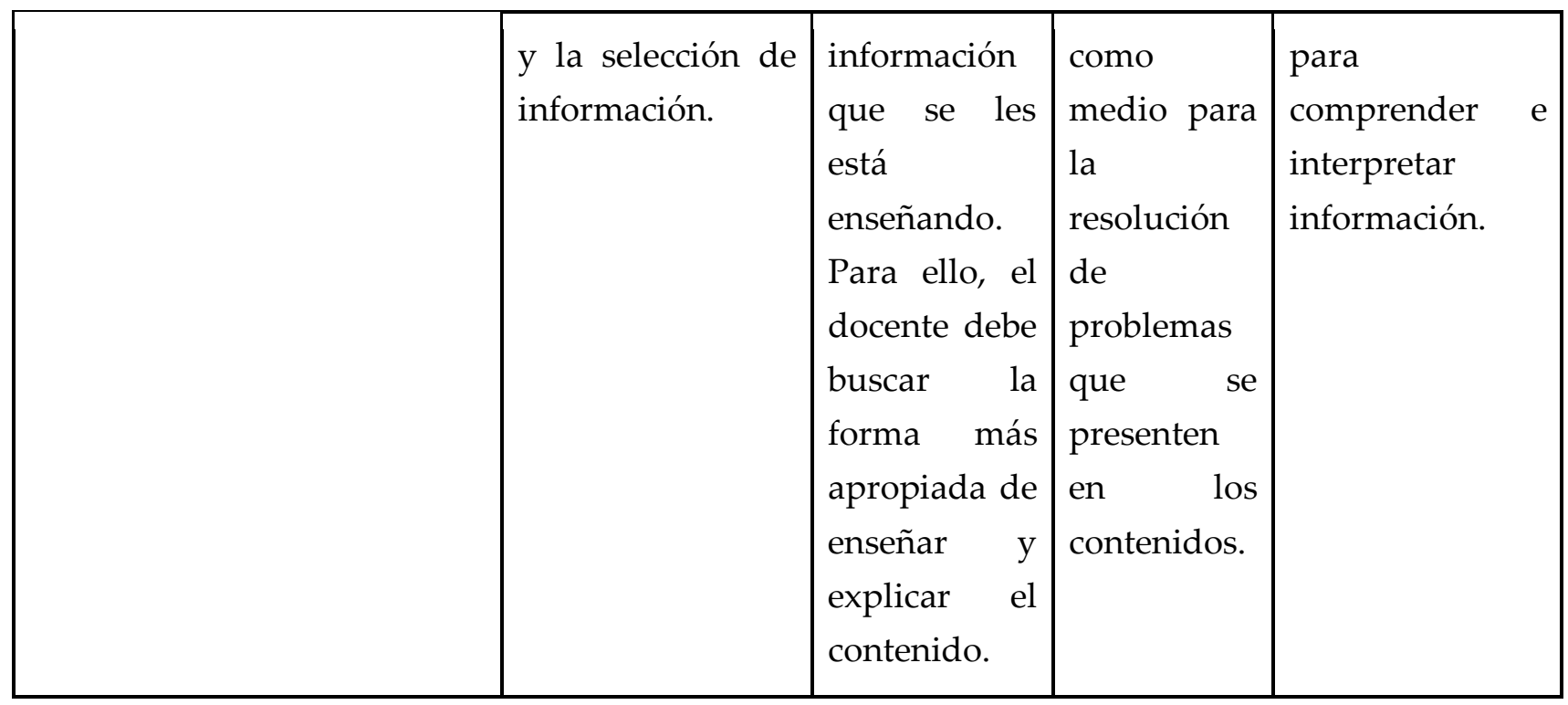

Fuente: Elaboración propia.

Tabla 3. Comparación tercer nivel taxonómico.

\begin{tabular}{|c|c|c|c|c|c|}
\hline \multicolumn{1}{|c|}{ Autores } & \multicolumn{1}{c|}{$\begin{array}{c}\text { Bloom } \\
(1956)\end{array}$} & $\begin{array}{c}\text { SOLO } \\
(1982)\end{array}$ & $\begin{array}{c}\text { Anderson } \\
(2001)\end{array}$ & $\begin{array}{c}\text { Fink } \\
(2003)\end{array}$ & $\begin{array}{c}\text { Marzano } \\
(2007)\end{array}$ \\
\hline Tercer nivel & Aplicación & Multiestructural & Aplicar & Integración & Análisis \\
\hline Adaptación & $\begin{array}{l}\text { Conceptos y elementos comunes } \\
\text { adaptación de contenidos para lograr los propósitos o metas establecidos } \\
\text { por el docente. El alumno debe adaptarse a nuevos desafíos de aprendizaje } \\
\text { para lograr una mayor comprensión de contenidos llevándolo a otros } \\
\text { ámbitos educativos. }\end{array}$ \\
\hline Contextualización & $\begin{array}{l}\text { Bloom, Anderson y Fink llevan la aplicación de contenidos a distintos } \\
\text { contextos sociales. Para el docente es una herramienta de mucha utilidad, } \\
\text { que puede integrarse dentro del aula para enseñar contenidos con el fin de } \\
\text { facilitar el aprendizaje utilizando información de contingencia e interés. }\end{array}$ \\
\hline problemas & $\begin{array}{l}\text { La aplicación busca que los alumnos sean capaces de resolver problemas a } \\
\text { través de los instrumentos entregados en el proceso de enseñanza } \\
\text { aprendizaje. Con esto se busca desafiar las capacidades de los alumnos para }\end{array}$ \\
\hline
\end{tabular}




\begin{tabular}{|c|c|c|c|c|}
\hline & \multicolumn{4}{|c|}{$\begin{array}{l}\text { que, a través de estos problemas, adquieran una educación integral capaz } \\
\text { de prepararlos ante eventuales situaciones que requieran de una resolución. }\end{array}$} \\
\hline \multicolumn{5}{|c|}{ Elementos diferenciadores } \\
\hline $\begin{array}{r}\text { Bloom } \\
(1956)\end{array}$ & $\begin{array}{l}\text { SOLO } \\
(1982)\end{array}$ & $\begin{array}{l}\text { Anderson } \\
(2001)\end{array}$ & $\begin{array}{c}\text { Fink } \\
(2003)\end{array}$ & $\begin{array}{l}\text { Marzano } \\
(2007)\end{array}$ \\
\hline $\begin{array}{l}\text { A través del contenido } \\
\text { entregado el estudiante debe ser } \\
\text { capaz de elaborar estrategias que } \\
\text { faciliten el desarrollo del } \\
\text { ejercicio. }\end{array}$ & $\begin{array}{l}\text { El estudiante es } \\
\text { capaz de } \\
\text { realizar su } \\
\text { trabajo } \\
\text { utilizando más } \\
\text { de una fuente } \\
\text { de } \\
\text { información, } \\
\text { realizando un } \\
\text { proceso de } \\
\text { análisis de } \\
\text { manera } \\
\text { gradual. }\end{array}$ & $\begin{array}{l}\text { Las acciones e } \\
\text { interacciones } \\
\text { que se } \\
\text { generan en el } \\
\text { proceso } \\
\text { formativo } \\
\text { pueden ser } \\
\text { empleados } \\
\text { por los } \\
\text { estudiantes en } \\
\text { distintos } \\
\text { contextos } \\
\text { sociales. }\end{array}$ & $\begin{array}{l}\text { El } \\
\text { estudiante } \\
\text { debe ser } \\
\text { capaz de } \\
\text { utilizar los } \\
\text { conocimien } \\
\text { tos e ideas } \\
\text { adquiridas } \\
\text { en el } \\
\text { proceso de } \\
\text { aprendizaje } \\
\text { en } \\
\text { diferentes } \\
\text { entornos } \\
\text { sociales. }\end{array}$ & $\begin{array}{l}\text { El } \\
\text { estudiante } \\
\text { es capaz de } \\
\text { utilizar } \\
\text { diversos } \\
\text { métodos de } \\
\text { trabajo con } \\
\text { el fin de } \\
\text { llegar a una } \\
\text { información } \\
\text { concreta. }\end{array}$ \\
\hline
\end{tabular}

Fuente: Elaboración propia.

Tabla 4. Comparación cuarto nivel taxonómico.

\begin{tabular}{|c|c|c|c|c|c|}
\hline Autores & $\begin{array}{l}\text { Bloom } \\
(1956)\end{array}$ & $\begin{array}{l}\text { SOLO } \\
(1982)\end{array}$ & $\begin{array}{l}\text { Anderson } \\
(2001)\end{array}$ & $\begin{array}{l}\text { Fink } \\
(2003)\end{array}$ & $\begin{array}{l}\text { Marzano } \\
(2007)\end{array}$ \\
\hline Cuarto nivel & Análisis. & Relacional. & Analizar. & $\begin{array}{l}\text { Dimensión } \\
\text { humana. }\end{array}$ & Aplicación. \\
\hline \multicolumn{6}{|c|}{ Conceptos y elementos comunes } \\
\hline $\begin{array}{c}\text { Averiguar, buscar } \\
\text { o identificar }\end{array}$ & \multicolumn{5}{|c|}{$\begin{array}{l}\text { Durante el proceso de trabajo la recolección, recopilación y la organización } \\
\text { de información es crucial para hallar la respuesta deseada. Por lo tanto, los } \\
\text { alumnos deben ser capaces de realizar un estudio previo o conocer ciertos }\end{array}$} \\
\hline
\end{tabular}

104 | INTEREDU № 1 Vol. I (DicIEMBRE 2019) PÁGS. 95-119. ISSN 2735-6523 


\begin{tabular}{|c|c|c|c|c|c|}
\hline & \multicolumn{5}{|c|}{$\begin{array}{l}\text { aspectos de la información y poder interpretarla según las capacidades de } \\
\text { cada estudiante. }\end{array}$} \\
\hline Competencia & \multicolumn{5}{|c|}{$\begin{array}{l}\text { Ya sea de manera individual o grupal, el proceso de análisis conlleva cierto } \\
\text { nivel de competencia, en este sentido. Cada respuesta o información } \\
\text { obtenida de este proceso de trabajo puede ser comparada por el docente } \\
\text { para encontrar elementos de relación o diferenciación. El aspirar a un } \\
\text { mismo objetivo conlleva a la motivación y la disputa, actividades que giran } \\
\text { en torno al análisis y conllevan al desarrollo de las capacidades de cada } \\
\text { estudiante. }\end{array}$} \\
\hline $\begin{array}{l}\text { Creación de } \\
\text { conjeturas }\end{array}$ & \multicolumn{5}{|c|}{$\begin{array}{l}\text { Las opiniones y conjeturas son importantes a la hora de analizar un } \\
\text { determinado fenómeno. Con ayuda de la experiencia, de los conocimientos } \\
\text { que tengamos de nuestro entorno o de realidad social en la que estamos } \\
\text { inmersos, podemos elaborar ciertos argumentos que puedan ser de utilidad } \\
\text { para elaborar una respuesta que de explicación al problema. }\end{array}$} \\
\hline $\begin{array}{l}\text { Descomposición y } \\
\text { relación de } \\
\text { información }\end{array}$ & \multicolumn{5}{|c|}{$\begin{array}{l}\text { Al realizar el análisis se debe llevar a cabo un proceso de descomposición } \\
\text { de información. Es decir, toda la información recabada debe ser separada y } \\
\text { estudiada de forma independienten para encontrar la relación existente } \\
\text { entre los demás elementos presentes en el fenómeno. De esta forma, se } \\
\text { podrá llegar a obtener información sustentada en base a buenos } \\
\text { argumentos. }\end{array}$} \\
\hline \multicolumn{6}{|c|}{ Elementos diferenciadores } \\
\hline $\begin{array}{l}\text { Bloom } \\
(1956)\end{array}$ & & $\begin{array}{l}\text { SOLO } \\
(1982)\end{array}$ & $\begin{array}{l}\text { Anderson } \\
(2001)\end{array}$ & $\begin{array}{c}\text { Fink } \\
(2003)\end{array}$ & $\begin{array}{l}\text { Marzano } \\
(2007)\end{array}$ \\
\hline \multicolumn{2}{|c|}{$\begin{array}{l}\text { Se procede cumpliendo con } \\
\text { estándares más estrictos, } \\
\text { realizando un análisis } \\
\text { detallado de toda la } \\
\text { información entregada. De } \\
\text { esta forma se podrán hallar } \\
\text { conceptos implícitos que } \\
\text { necesiten de la opinión e } \\
\text { interpretación individual de }\end{array}$} & $\begin{array}{l}\text { Etapa en la cual } \\
\text { se realiza un } \\
\text { análisis } \\
\text { integral. Es } \\
\text { decir, no se } \\
\text { concentra en } \\
\text { conceptos } \\
\text { específicos, } \\
\text { sino que abarca }\end{array}$ & 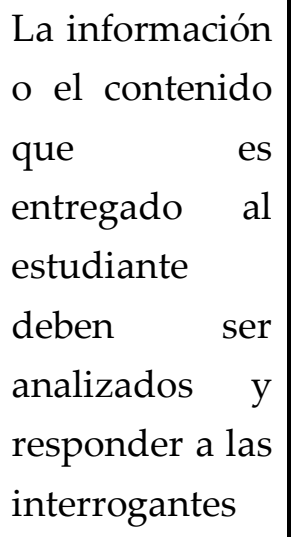 & $\begin{array}{lr}\text { Se deja } & \text { de } \\
\text { lado } & \text { el } \\
\text { análisis } & \text { de } \\
\text { información o } \\
\text { la } & \text { resolución } \\
\text { de } & \\
\text { problemas. } \\
\text { Aquí lo } \\
\text { importantes }\end{array}$ & $\begin{array}{l}\text { El } \\
\text { conocimient } \\
\text { o adquirido } \\
\text { y aprendido } \\
\text { por el } \\
\text { estudiante } \\
\text { influye a la } \\
\text { hora de } \\
\text { tomar }\end{array}$ \\
\hline
\end{tabular}




\begin{tabular}{|c|c|c|c|c|}
\hline $\begin{array}{l}\text { cada estudiante para su } \\
\text { explicación. }\end{array}$ & $\begin{array}{l}\text { toda la } \\
\text { información } \\
\text { disponible, } \\
\text { realizando un } \\
\text { proceso de } \\
\text { descripción } \\
\text { para combinar } \\
\text { ideas y dar } \\
\text { solución al } \\
\text { problema en } \\
\text { cuestión. }\end{array}$ & $\begin{array}{l}\text { que se refieran } \\
\text { a la relación } \\
\text { que existe en } \\
\text { ciertos } \\
\text { conceptos o } \\
\text { ideas con la } \\
\text { información } \\
\text { global. }\end{array}$ & $\begin{array}{l}\text { es que el } \\
\text { alumno } \\
\text { pueda } \\
\text { realizar una } \\
\text { observación } \\
\text { hacia su } \\
\text { persona y } \\
\text { hacia su } \\
\text { entorno } \\
\text { social, } \\
\text { conociendo } \\
\text { las fortalezas } \\
\text { y debilidades } \\
\text { que poseen. }\end{array}$ & $\begin{array}{l}\text { decisiones. } \\
\text { En caso de } \\
\text { presentarse } \\
\text { un } \\
\text { problema, el } \\
\text { alumno } \\
\text { tendrá las } \\
\text { capacidades } \\
\text { necesarias } \\
\text { para dar una } \\
\text { respuesta o } \\
\text { solución } \\
\text { concisa. }\end{array}$ \\
\hline
\end{tabular}

Fuente: Elaboración propia.

Tabla 5. Comparación quinto nivel taxonómico.

\begin{tabular}{|l|l|l|c|c|c|}
\hline Autores & $\begin{array}{l}\text { Bloom } \\
(1956)\end{array}$ & \multicolumn{1}{|c|}{$\begin{array}{c}\text { SOLO } \\
(1982)\end{array}$} & $\begin{array}{c}\text { Anderson } \\
(2001)\end{array}$ & $\begin{array}{c}\text { Fink } \\
(2003)\end{array}$ & $\begin{array}{c}\text { Marzano } \\
(2007)\end{array}$ \\
\hline Quinto nivel & Síntesis & $\begin{array}{l}\text { Abstracto } \\
\text { ampliado. }\end{array}$ & Evaluar. & Cuidado. & Metacognición. \\
\hline Elaborar & \multicolumn{3}{|c|}{ Conceptos y elementos comunes } \\
\hline & $\begin{array}{l}\text { Los estudiantes son capaces de utilizar el contenido visto y, por medio de } \\
\text { este, poder elaborar diferentes propuestas, usarlo en diferentes contextos, } \\
\text { buscar nuevos métodos y formas de utilizarlo, apropiándose del contenido } \\
\text { aprendido. }\end{array}$ \\
\hline Autonomía & $\begin{array}{l}\text { Es la capacidad de los alumnos de poder llegar a enriquecer su propia } \\
\text { formación, investigando o reforzando sus aprendizajes sin necesidad de un } \\
\text { guía en aquel proceso. }\end{array}$ \\
\hline $\begin{array}{l}\text { Aprendizaje } \\
\text { significativo }\end{array}$ & $\begin{array}{l}\text { Es aquel aprendizaje que es adquirido durante todo el proceso educativo. } \\
\text { Puede ser utilizado en distintos contextos y ámbitos de la vida del } \\
\text { estudiante, no se olvida y se mantiene en las capacidades del alumno. }\end{array}$ \\
\hline
\end{tabular}

106 | INTEREDU № 1 VOL. I(DiCIEMBRe 2019) PÁGs. 95-119. ISSN 2735-6523 


\begin{tabular}{|c|c|c|c|c|}
\hline \multicolumn{5}{|c|}{ Elementos diferenciadores } \\
\hline $\begin{array}{l}\text { Bloom } \\
\text { (1956) }\end{array}$ & $\begin{array}{l}\text { SOLO } \\
(1982)\end{array}$ & $\begin{array}{c}\text { Anderson } \\
(2001)\end{array}$ & $\begin{array}{l}\text { Fink } \\
(2003)\end{array}$ & $\begin{array}{c}\text { Marzano } \\
(2007)\end{array}$ \\
\hline $\begin{array}{l}\text { Las ideas complementarias, } \\
\text { elaboradas por el } \\
\text { estudiante, están } \\
\text { relacionadas con su propia } \\
\text { experiencia con el fin de } \\
\text { elaborar reflexiones propias } \\
\text { complementadas con los } \\
\text { conocimientos previos. }\end{array}$ & $\begin{array}{l}\text { El estudiante es } \\
\text { capaz de llevar } \\
\text { todo el } \\
\text { conocimiento } \\
\text { adquirido y } \\
\text { establecer } \\
\text { relaciones con } \\
\text { distintos } \\
\text { contextos } \\
\text { sociales y } \\
\text { elementos } \\
\text { externos, ya que } \\
\text { ha cumplido con } \\
\text { las etapas o } \\
\text { procesos que le } \\
\text { permiten } \\
\text { adueñarse de } \\
\text { aquel contenido } \\
\text { y trabajarlo } \\
\text { como crean } \\
\text { necesario. }\end{array}$ & $\begin{array}{l}\text { Los } \\
\text { argumentos } \\
\text { que se } \\
\text { elaboran o se } \\
\text { crean están } \\
\text { condicionados } \\
\text { a los criterios } \\
\text { que el profesor } \\
\text { establece. }\end{array}$ & $\begin{array}{l}\text { Toma el } \\
\text { proceso } \\
\text { formativo } \\
\text { como un } \\
\text { contexto } \\
\text { que } \\
\text { fortalece al } \\
\text { individuo } \\
\text { perfeccion } \\
\text { ando sus } \\
\text { habilidade } \\
\text { s, intereses } \\
\text { y valores. }\end{array}$ & $\begin{array}{l}\text { Todas las ideas } \\
\text { generadas por } \\
\text { los estudiantes } \\
\text { son } \\
\text { combinadas y } \\
\text { relacionadas } \\
\text { para elaborar } \\
\text { un producto } \\
\text { final, ya sea en } \\
\text { un trabajo, un } \\
\text { plan o una } \\
\text { propuesta, } \\
\text { incentivando la } \\
\text { creatividad } \\
\text { individual de } \\
\text { cada alumno. }\end{array}$ \\
\hline
\end{tabular}

Fuente: Elaboración propia.

Tabla 6. Comparación sexto nivel taxonómico.

\begin{tabular}{|l|c|c|c|l|}
\hline Autores & $\begin{array}{c}\text { Bloom } \\
(1956)\end{array}$ & $\begin{array}{c}\text { Anderson } \\
(2001)\end{array}$ & $\begin{array}{c}\text { Fink } \\
(2003)\end{array}$ & $\begin{array}{c}\text { Marzano } \\
(2007)\end{array}$ \\
\hline Sexto nivel & Evaluación & Crear & $\begin{array}{c}\text { Aprendiendo a } \\
\text { aprender }\end{array}$ & $\begin{array}{l}\text { Sistema de } \\
\text { conocimiento del } \\
\text { ser }\end{array}$ \\
\hline
\end{tabular}




\section{Conceptos y elementos comunes}

Es el proceso por el cual el estudiante distingue la información que se le

Investigar presenta para identificar los datos que sean correctos, adecuados y que tengan relación con los contenidos estudiados.

Discernir

El alumno debe ser capaz de desarrollar argumentos con los cuales sustente las nuevas ideas, las respuestas o los progresos de su investigación.

Confeccionar

Se debe desarrollar los pilares en los cuales fundamentar cada concepto e idea utilizada, por lo cual el estudiante tiene que idear un plan de acción para llevar a cabo el reconocimiento de dicha información.

\section{Elementos diferenciadores}

\begin{tabular}{|c|c|c|c|}
\hline $\begin{array}{l}\text { Bloom } \\
\text { (1956) }\end{array}$ & $\begin{array}{c}\text { Anderson } \\
(2001)\end{array}$ & $\begin{array}{l}\text { Fink } \\
(2003)\end{array}$ & $\begin{array}{c}\text { Marzano } \\
(2007)\end{array}$ \\
\hline $\begin{array}{l}\text { Se pone mayor énfasis en el } \\
\text { análisis del docente en las } \\
\text { respuestas subjetivas de sus } \\
\text { alumnos, presentando un } \\
\text { modelo más libre a la hora de } \\
\text { valorar los argumentos. }\end{array}$ & $\begin{array}{l}\text { A través de los } \\
\text { conocimientos } \\
\text { adquiridos el } \\
\text { estudiante es } \\
\text { capaz de crear } \\
\text { nuevas formas } \\
\text { de trabajo que } \\
\text { completen las } \\
\text { habilidades y } \\
\text { metodologías de } \\
\text { aprendizaje. }\end{array}$ & $\begin{array}{l}\text { Se fortalece la } \\
\text { autonomía del } \\
\text { alumno. Es decir, que } \\
\text { mediante el proceso de } \\
\text { investigación y los } \\
\text { cuestionamientos que } \\
\text { de ahí surjan, y a la } \\
\text { posterior corrección } \\
\text { podrá desempeñar su } \\
\text { labor autónoma de } \\
\text { aprendizaje. }\end{array}$ & $\begin{array}{l}\text { La importancia } \\
\text { de las creencias y } \\
\text { emociones al } \\
\text { momento de } \\
\text { adquirir es vital a } \\
\text { la hora de } \\
\text { comprender un } \\
\text { aprendizaje. }\end{array}$ \\
\hline
\end{tabular}

Fuente: Elaboración propia.

\subsection{SEGUNDA CATEGORÍA}

Siguiendo el modelo explicativo de la categoría de propósitos, en esta segunda categoría se presenta el modelo de organización y la manera en cómo establecen la planificación didáctica de los contenidos, mostrando de manera evidente aquellos procesos que pretenden ordenar y estructurar la forma de ver los objetivos y temas.

Para ejemplificar aquellos temas de manera concreta y poder identificar las diferencias, se toma como ejemplo el libro de Lenguaje y Comunicación, tercero medio (SM, 108 | INTEREDU № 1 Vol. I (DicIEMBRE 2019) PÁGS. 95-119. ISSN 2735-6523 
2020, Unidad 1 "Héroes y Villanos", lección 3 de textos informativos. El propósito de mostrar estas ideas es para reconocer las diferencias de uso y aplicación de cada una de estas taxonomías por medio de objetivos y actividades que se consideran para la planificación del acto didáctico en el aula.

Tabla 7. Principales procesos considerados en taxonomía de Bloom (1956).

\begin{tabular}{|l|l|l|}
\hline Bloom (1956) & \multicolumn{1}{|c|}{ Objetivos } & \multicolumn{1}{|c|}{ Actividades } \\
\hline Conocimiento & $\begin{array}{l}\text { Se muestra las partes y los } \\
\text { recursos discursivos del } \\
\text { texto informativo. }\end{array}$ & $\begin{array}{l}\text { Define las partes del texto } \\
\text { informativo. }\end{array}$ \\
\hline Comprensión & $\begin{array}{l}\text { Presenta diferentes textos } \\
\text { informativos con diferente } \\
\text { información. }\end{array}$ & $\begin{array}{l}\text { Distingue las partes, el } \\
\text { recurso discursivo y el tipo } \\
\text { de texto informativo } \\
\text { utilizado }\end{array}$ \\
\hline Aplicación & $\begin{array}{l}\text { Enseña que los textos } \\
\text { informativos se utilizan en } \\
\text { distintos contextos o } \\
\text { situaciones. }\end{array}$ & $\begin{array}{l}\text { Aplica los contenidos } \\
\text { aprendidos creando un } \\
\text { texto informativo. }\end{array}$ \\
\hline Análisis & $\begin{array}{l}\text { Recuerda las partes del } \\
\text { texto informativo. }\end{array}$ & $\begin{array}{l}\text { Ordena un } \\
\text { informativo que } \\
\text { encuentra desordenado. }\end{array}$ \\
\hline Síntesis & $\begin{array}{l}\text { Presenta diversas formas y } \\
\text { tipos de textosinformativos. }\end{array}$ & $\begin{array}{l}\text { Diseña un nuevo modelo } \\
\text { capaz de abordar el texto } \\
\text { informativo. }\end{array}$ \\
\hline Evaluación & $\begin{array}{l}\text { Observar las presentaciones } \\
\text { de los alumnos. }\end{array}$ & $\begin{array}{l}\text { De acuerdo al modelo } \\
\text { informativo } \\
\text { argumenta por qué decidiste } \\
\text { tomar aquellas elecciones. }\end{array}$ \\
\hline
\end{tabular}

Fuente: Elaboración propia. 
Tabla 8. Principales procesos considerados en taxonomía de SOLO (1982).

\begin{tabular}{|c|c|c|}
\hline SOLO (1982) & Objetivos & Actividades \\
\hline Preestructural & $\begin{array}{l}\text { Introducir y mostrar el } \\
\text { contenido que se enseñará. }\end{array}$ & $\begin{array}{l}\text { El estudiante contesta un } \\
\text { cuestionario relacionado } \\
\text { con los contenidos. }\end{array}$ \\
\hline Uniestructural & $\begin{array}{l}\text { Comentar aspectos e } \\
\text { información del texto } \\
\text { informativo. }\end{array}$ & $\begin{array}{l}\text { Los estudiantes realizan } \\
\text { una comprensión lectora de } \\
\text { contenidos para realizar un } \\
\text { espacio de preguntas y } \\
\text { respuestas con el docente. }\end{array}$ \\
\hline Multiestructural & $\begin{array}{l}\text { Extiende la explicación de } \\
\text { los contenidos y las } \\
\text { contrasta con otras fuentes } \\
\text { de información. }\end{array}$ & $\begin{array}{l}\text { Revisar distintos textos } \\
\text { informativos e identificar } \\
\text { las diferencias presentes en } \\
\text { sus partes y recursos } \\
\text { utilizados. }\end{array}$ \\
\hline Relacional & $\begin{array}{l}\text { Investigar un fenómeno } \\
\text { presente en su entorno. }\end{array}$ & $\begin{array}{l}\text { En base al contenido dar } \\
\text { solución a los problemas } \\
\text { presentes en el entorno. }\end{array}$ \\
\hline Abstracto ampliado & $\begin{array}{l}\text { Analizar los fenómenos } \\
\text { encontrados } \\
\text { investigación. }\end{array}$ & $\begin{array}{l}\text { Con la información } \\
\text { recabada } \\
\text { informe. }\end{array}$ \\
\hline
\end{tabular}

Fuente: Elaboración propia.

Tabla 9. Principales procesos considerados en la taxonomía de Anderson (2001).

\begin{tabular}{|l|l|l|}
\hline Anderson (2001) & Objetivos & Actividades \\
\hline Recordar & $\begin{array}{l}\text { Señalar a los estudiantes la } \\
\text { relación existente entre el } \\
\text { texto informativo con los } \\
\text { productos que ellos ya han } \\
\text { visto. }\end{array}$ & $\begin{array}{l}\text { Lostudiantes observan } \\
\text { distintos tipos de texto } \\
\text { informativos. }\end{array}$ \\
\hline Comprender & $\begin{array}{l}\text { El docente busca interpolar } \\
\text { los contenidos nuevos con } \\
\text { los que los alumnos ya } \\
\text { manejan para poder lograr } \\
\text { un aprendizaje integral. }\end{array}$ & $\begin{array}{l}\text { Relacionar los pues } \\
\text { informativos presentados } \\
\text { quen diversas situaciones } \\
\text { contextos. }\end{array}$ \\
\hline
\end{tabular}




\begin{tabular}{|c|c|c|}
\hline Aplicar & $\begin{array}{l}\text { Clasificar información } \\
\text { presente en diferentes } \\
\text { textos informativos. }\end{array}$ & $\begin{array}{l}\text { Leer un texto informativo, } \\
\text { identificar sus partes y } \\
\text { recursos } \\
\text { utilizados. }\end{array}$ \\
\hline Analizar & $\begin{array}{l}\text { Analizar diferentes fuentes } \\
\text { de información referentes al } \\
\text { texto informativo. }\end{array}$ & $\begin{array}{l}\text { Comparar las diferentes } \\
\text { opciones de textos } \\
\text { informativos que puede } \\
\text { haber y compararlos. }\end{array}$ \\
\hline Evaluar & $\begin{array}{l}\text { Argumentar las diferentes } \\
\text { posturas de los estudiantes } \\
\text { hacia una información en } \\
\text { particular }\end{array}$ & $\begin{array}{l}\text { Los estudiantes discutirán } \\
\text { acerca de una noticia en } \\
\text { particular, comparando y } \\
\text { sus opiniones frente al tema. }\end{array}$ \\
\hline Crear & $\begin{array}{llr}\text { Construir } & \text { un } & \text { texto } \\
\text { informativo } & \text { de } & \text { manera } \\
\text { innovadora. } & & \\
& & \end{array}$ & $\begin{array}{l}\text { Los estudiantes deben } \\
\text { elaborar un texto } \\
\text { informativo que escape de } \\
\text { las normas ya establecidas, } \\
\text { ofreciendo una nueva } \\
\text { metodología y forma de ver } \\
\text { a este. }\end{array}$ \\
\hline
\end{tabular}

Fuente: Elaboración propia.

En la taxonomía de Fink (2011) se encuentra un detalle que representa una diferencia importante con las demás taxonomías. El uso de verbos no se encuentra especificado, por lo cual, se complementa utilizando verbos de otras taxonomías, como por ejemplo la de Anderson o la de SOLO, Bloom se deja excluida de este complemento ya que esta utiliza sustantivos y no se adecua a los planteamientos realizados por Fink. Se puede inferir de lo anterior que dicha taxonomía busca la libertad por parte del docente para llevar a cabo los resultados de aprendizajes que se adecuen a aquellos planteamientos, sin dejar de lado los propósitos establecidos por este. Por tanto, no se tiene una lista de verbos preestablecidos.

Considerando estos planteamientos debemos decir que se adecuan con el propósito propuesto por Fink, esto es, los verbos cumplen una labor fundamental en la planificación porque son estos los que permiten planificar, con anticipación, los objetivos de aprendizajes de una unidad. En este sentido se pone énfasis en los niveles superiores, si habláramos de la taxonomía de Anderson (2001), en específico los niveles serían el de análisis, evaluación y creación porque son estos los que permiten al docente comprobar el aprendizaje significativo de los estudiantes por medio de aplicación y reelaboración de contenidos en distintos contextos. 
Tabla 10. Principales procesos considerados en taxonomía de Marzano (2007).

\begin{tabular}{|c|c|c|}
\hline Marzano (2007) & Objetivos & Actividades \\
\hline Recuperación & $\begin{array}{l}\text { Definir las partes de un } \\
\text { texto informativo. }\end{array}$ & $\begin{array}{l}\text { Realizar cuestionario sobre } \\
\text { las partes y los recursos del } \\
\text { texto informativo. }\end{array}$ \\
\hline Comprensión & $\begin{array}{l}\text { Reafirmar los contenidos } \\
\text { vistos con anterioridad. }\end{array}$ & $\begin{array}{l}\text { Identificar las partes del } \\
\text { texto informativo y el } \\
\text { recurso discursivo utilizado } \\
\text { en los ejemplos propuestos. }\end{array}$ \\
\hline Análisis & $\begin{array}{l}\text { Contrastar las respuestas y } \\
\text { argumentos de los } \\
\text { estudiantes basados en las } \\
\text { conjeturas presentadas de } \\
\text { acuerdo a un texto } \\
\text { informativo. }\end{array}$ & $\begin{array}{l}\text { Analiza los siguientes textos } \\
\text { informativos y responde las } \\
\text { siguientes preguntas. }\end{array}$ \\
\hline Aplicación & $\begin{array}{l}\text { Resolver problemas de } \\
\text { orden y redacción en un } \\
\text { texto informativo. }\end{array}$ & $\begin{array}{l}\text { Ordenar la estructura y } \\
\text { corregir la redacción de los } \\
\text { siguientes } \\
\text { informativos. }\end{array}$ \\
\hline Metacognición & $\begin{array}{l}\text { Proponer ideas para realizar } \\
\text { una investigación en base a } \\
\text { los pilares fundamentales } \\
\text { del texto informativo. }\end{array}$ & $\begin{array}{l}\text { En grupos de } 4 \text { personas } \\
\text { investiga sobre los pilares } \\
\text { que llevaron a la creación de } \\
\text { los textos informativos. }\end{array}$ \\
\hline $\begin{array}{l}\text { Sistema de conocimiento } \\
\text { del ser }\end{array}$ & $\begin{array}{l}\text { Valorar el contenido del } \\
\text { trabajo investigativo. }\end{array}$ & $\begin{array}{l}\text { Explicar y autoevaluar la } \\
\text { investigación realizada. }\end{array}$ \\
\hline
\end{tabular}

Fuente: Elaboración propia.

\section{RESUltADOS Y PROPUESTA DE MODELO TAXONÓMICO}

En la siguiente propuesta, presentamos un modelo taxonómico que rescate, de acuerdo a nuestra percepción y estudio, lo más adecuado de cada taxonomía para ser ajustado al propósito planteado, que es el reforzamiento de contenidos para la asignatura de Lengua y Literatura. 


\section{PRIMER NIVEL: FINK “CONOCIMIENTO FUNDACIONAL”}

- Definición: Poder recordar información e ideas.

- Elemento diferenciador: Se comprende información a través de diferentes ideas que cada estudiante haya aprendido o conocido con anterioridad.

- Justificación: El haber posicionado a Fink en el primer nivel surge de la idea de cómo este autor propone ordenar los contenidos que son recordados por los alumnos y abordados por el docente centrándose en la idea que pueden trabajarse en el proceso didáctico en aula. No hay limitantes que condicionan la memoria de los estudiantes, sino que la forma de recordar la información resulta totalmente libre. Evidentemente las ideas deben tener relación con el contenido que será abordado pero el estudiante al tener la libertad de recordar información y relacionarla con otros aspectos, permite distinguir y evidenciar los planteamientos que deberán ser trabajados. Además, no solo se limita al accionar de los estudiantes, el docente puede implementar estrategias que permitan favorecer el recuerdo de los alumnos, por ejemplo, llevando material como imágenes, vídeos, esquemas y cuadros.

\section{SEGUNDO NIVEL: ANDERSON “COMPRENDER”}

- Definición: Construir significado a partir de material educativo, como la lectura o las explicaciones del docente.

- Elemento diferenciador: El objetivo es que los estudiantes le den un significado a la información que se les está enseñando, para ello el docente debe buscar la forma más apropiada de enseñar y explicar el contenido.

- Justificación: El segundo nivel fue seleccionado en función de poder reforzar la información e ideas que en el primer nivel fueron presentadas. Por ello es necesario darle un significado a aquel material por medio de diferentes medios didácticos, como por ejemplo, recurriendo a textos que de cierta manera venga a apoyar el desarrollo del aprendizaje.

\section{TERCER NIVEL: SOLO “MULTIESTRUCTURAL”}

- Definición: Respuestas que utilizan más datos informativos, que son analizados de manera separada.

- Elemento diferenciador: El estudiante es capaz de utilizar diversos métodos de trabajo con el fin de llegar a una información concreta.

- Justificación: El tercer nivel de SOLO fue escogido por la importancia que se le da a la búsqueda de nueva información. El estudiante no se limita solo a los medios 
didácticos, sino que se les permite consultar diferentes fuentes informativas que puedan ser utilizadas para complementar el aprendizaje. Además de la investigación y recolección de datos hay un proceso de análisis en el cual deben identificar la validez de la información consultada usando un proceso de comparación.

\section{CUARTO NIVEL: BLOOM “APLICACIÓN”}

- Definición: El alumno pone a prueba la información adquirida en actividades específicas que buscan desafiar sus conocimientos, a través de la resolución de problemas. En este punto el alumno utiliza estrategias que faciliten el desarrollo del ejercicio utilizando los recursos que antes adquirió.

- Elemento diferenciador: A través del contenido entregado el estudiante debe ser capaz de elaborar estrategias que faciliten el desarrollo del ejercicio.

- Justificación: Una vez desarrollado el tema en cuestión, pasando por el proceso de recordar, reforzar y analizar, es importante aplicar, por lo tanto, el cuarto nivel estará poniendo a prueba los procesos de aprendizajes ya trabajados, buscando que el alumno pueda desarrollar su habilidad en la resolución de problemas, trabajando más exhaustivamente los contenidos ya vistos.

\section{QUINTO NIVEL: MARZANO “SISTEMA DE CONOCIMIENTO DEL SER”}

- Definición: El estudiante es capaz de determinar e identificar la importancia que poseen sus creencias y emociones al momento de comprender un determinado conocimiento.

- Elemento diferenciador: La importancia de las creencias y emociones al momento de adquirir es vital a la hora de comprender un aprendizaje.

- Justificación: Para complementar los conocimientos adquiridos a lo largo del proceso educativo es relevante considerar las creencias y emociones de los estudiantes para revisar y reforzar los contenidos ya vistos. De esta forma, se integran y consideran las opiniones que los estudiantes conciben al momento de trabajar el material de estudio. Debemos evidenciar la importancia que tiene esta instancia para que los conocimientos sean integrados fácilmente, reforzando la forma en cómo los alumnos adquieran, complementen y refuercen dicho aprendizaje. Este proceso es enriquecedor porque permite conocer las diferentes posturas que cada estudiante tiene, haciendo énfasis en conocerse más entre compañeros y ser tolerantes con la ideología de los demás. 


\section{SEXTO NIVEL: ANDERSON “CREAR”}

- Definición: A partir del contenido asimilado poder hacer algo original creando, mejorando y optimizando aquel aprendizaje.

- Elemento diferenciador: A través de los conocimientos adquiridos el estudiante es capaz de crear nuevas formas de trabajo que completen las habilidades y metodologías de aprendizaje.

- Justificación: Si bien la evaluación no está establecida en un nivel propio debemos mencionar que dentro de este último no solo se establece una creación de material o contenidos que mejoren el aprendizaje. Las evaluaciones también tienen un papel fundamental en este nivel, pues son ellas donde los estudiantes elaboran y crean argumentos que permitan al docente comprobar el aprendizaje adquirido por ellos. Por lo tanto, dichas evaluaciones deben considerar elementos que permitan al estudiante crear o elaborar respuestas propias que vengan a reforzar, en parte, la creación de nuevos contenidos, pero que no dejen de reflejar la adquisición de aprendizaje en los niveles anteriores.

En la siguiente tabla se grafica la propuesta estructurando cada uno de los niveles taxonómicos. Cabe destacar que para el primer nivel de Fink utilizamos verbos escogidos de la propuesta de Anderson, pues como habíamos mencionado antes, Fink da libertad al docente para escoger los verbos de otras taxonomías que se adecuen a los objetivos de enseñanza aprendizaje. Lo anterior implica una propuesta de ordenamiento y secuenciación didáctica para trabajar la planificación en base a las habilidades aquí identificadas.

Tabla 11. Propuesta de secuenciación de las habilidades al uso.

\begin{tabular}{|c|c|c|c|c|c|}
\hline Nivel 1: Fink & Nivel 2: Anderson & Nivel 3: Solo & Nivel 4: Bloom & Nivel 5: Marzano & Nivel 6: Anderson \\
\hline $\begin{array}{l}\text { Conocimiento } \\
\text { Fundacional }\end{array}$ & $\underline{\text { Comprender }}$ & $\underline{\text { Multiestructural }}$ & Aplicación & $\begin{array}{l}\text { Sistema de } \\
\text { conocimiento del } \\
\underline{\text { ser }}\end{array}$ & Crear \\
\hline $\begin{array}{l}\text { Se centra en la } \\
\text { recordación de } \\
\text { ideas y } \\
\text { contenidos, sin } \\
\text { elementos que } \\
\text { condicionen el } \\
\text { proceso de } \\
\text { aprendizaje. }\end{array}$ & $\begin{array}{l}\text { Reforzar } \\
\text { información } \\
\text { utilizando } \\
\text { diferentes } \\
\text { medios } \\
\text { didácticos. }\end{array}$ & $\begin{array}{l}\text { Complementar } \\
\text { contenidos } \\
\text { utilizando } \\
\text { nuevas fuentes } \\
\text { de } \\
\text { información, } \\
\text { realizando un } \\
\text { proceso de } \\
\text { análisis. }\end{array}$ & $\begin{array}{l}\text { Poner a prueba } \\
\text { las } \\
\text { investigacione } \\
\text { s a través de la } \\
\text { resolución de } \\
\text { problemas. }\end{array}$ & $\begin{array}{l}\text { Considerar los } \\
\text { elementos } \\
\text { relacionados } \\
\text { con las } \\
\text { emociones y } \\
\text { creencias de } \\
\text { los alumnos } \\
\text { para fomentar } \\
\text { el desarrollo } \\
\text { del } \\
\text { aprendizaie. }\end{array}$ & $\begin{array}{l}\text { Sintetizar todo } \\
\text { lo aprendido } \\
\text { elaborando } \\
\text { nuevos } \\
\text { contenidos y } \\
\text { métodos de } \\
\text { aprendizaje. }\end{array}$ \\
\hline
\end{tabular}

Fuente: Elaboración propia. 


\section{CONCLUSIONES}

El problema abordado en la presente investigación en base a la revisión documental realizada, está conectado con el orden, planificación y estructura de la actividad docente, buscando estrategias o métodos adecuados que logren reforzar los procesos de enseñanza aprendizaje.

Tal como se señaló anteriormente, en el currículum del área de Lenguaje y Comunicación se presentan tres ejes: lectura, escritura y comunicación oral, que se categorizó en este estudio en el nivel de organización-planificación, utilizando el contenido de los textos informativos. En este caso, debemos concluir que las taxonomías pueden adecuarse a los ejes y objetivos, permitiendo que cada uno de estos puedan llevarse a cabo, trabajando las habilidades que el currículum establece (Santaella, 2012).

El estudio realizado logra presentar la coherencia en la relación de objetivos, contenidos y actividades con distintas taxonomías. Del mismo modo, es posible establecer y estructurar las clases ya no pensando simplemente en qué debo enseñar, sino también en qué habilidad quiero reforzar, dando opciones a nuevos caminos de elección, donde el profesor es quien tiene la oportunidad de gestionar este conocimiento en función del alumno.

- Taxonomía de Bloom. Es un gran esfuerzo por jerarquizar las habilidades del pensamiento, clasificando los diferentes objetivos y habilidades que los docentes pueden proponer a sus estudiantes. No debemos dejar de lado que la taxonomía posee la dimensión afectiva, psicomotora y cognitiva, las cuales describen el modo como los seres humanos reaccionan emocionalmente, como manifiestan su pericia para manipular físicamente una herramienta, o en su caso la habilidad para pensar las cosas. Todo este esfuerzo viene a ser el punto de partida de la estructuración gráfica de una clase, donde se presentan ideas a modo de guía que refuerzan el trabajo del docente. Por otra parte, se presenta un modelo taxonómico que evalúa las subjetividades de las respuestas, no solo prestando atención en lo concreto, sino en los detalles y matices que permitieron llegar a aquella respuesta.

- Taxonomía de SOLO. Presenta un modelo abstracto, pero que a la vez viene a ser el modelo más concreto en cuanto a avances de aprendizajes se refiere. Se implementa una forma de trabajo instructiva que incentiva y profundiza en los interés y motivaciones de los estudiantes para adquirir el conocimiento necesario que será utilizado en otros contextos de manera adecuada. 
- Taxonomía de Anderson. Es una secuencia ordenada y lógica capacitando la creación de nuevos contenidos a través de la recepción de aprendizajes y la utilización de estos mismos en los nuevos planteamientos lo que provoca una creación o el perfeccionamiento de dichos aprendizajes. Todo esto supone que, al ser una secuencia de aprendizaje que busca llegar hasta el mayor nivel de complejidad en los niveles establecidos. La participación del estudiante se vuelve mayor, más profunda y comprometida en la construcción de su conocimiento, haciendo uso de las de herramientas mentales o materiales. Por lo tanto, son las categorías más complejas las que requieren de mayor esfuerzo mental, en el sentido de ser las que garantizan la adquisición y aplicación de competencias. Todo este proceso de aprendizaje permite al docente tener una visión compleja, asociando las acciones concretas que los alumnos pueden realizar en el aula o fuera de ella, como consecuencia de directrices ad hoc propuestas por el profesor.

- Taxonomía de Fink. Establece una idea completamente diferente a las anteriores. El aprendizaje no viene a ser un refuerzo de habilidades y conocimientos específicamente, más bien pretende que los alumnos tengan la capacidad de utilizar el conocimiento para desarrollarse como personas y tener conciencia de los individuos que les rodean. Además, promueve e inculca la autonomía para el futuro desarrollando y perfeccionando del aprendizaje que adquirieron. Todo esto con el propósito de formar un individuo capaz de adaptarse a las situaciones que requieran de sus conocimientos adquiridos.

- Taxonomía de Marzano. Está orientada al aprendizaje que se manifiesta en la oportunidad de cambio respecto de lo que la persona está haciendo o conociendo, al presentarse nuevas tareas. Ello, tomando en cuenta la importancia del autoconocimiento, las emociones, sentimientos y creencias de la persona, sus capacidades para establecer metas en su vida y su capacidad para definir acciones y evaluar estrategias para lograr esas metas. Todo este proceso está relacionado con el desarrollo metacognitivo del individuo. Esto cumple un rol fundamental dentro de la adquisición de conocimientos, pues es necesario que como docentes tengamos la capacidad de dar valor a las creencias y emociones de nuestros alumnos, ya que estas son las que delimitan la adquisición de sus nuevos aprendizajes. 


\section{REFERENCIAS BIBLIOGRÁFICAS}

Baena, A., \& Ruiz Montero, P. J. (2015). Taxonomía de objetivos y su valor didáctico para la educación física escolar. Murcia.

Bancayán Oré, C. (2013). Operacionalización de la taxonomía de Anderson y Krathwohl para la docencia universitaria. Paideia XXI.

Berríos Muñoz, A., Peralta Valdés, D., \& Vera Solís, P. (2020). Texto del estudiante Lengua y Literatura . Santiago: SM.

Bitar, S. (2011). Formación docente en Chile. Santiago.

Dugarte, A. M. (s.f.). Taxonomía educativa integradora como estrategia didáctica para la planificación instruccional. Revista ciencia de la educación. Educacionysociedad53. (8 de Mayo de 2017). Obtenido de https://educacionysociedad53.wordpress.com/2017/05/08/taxonomias-de-bloommarzano-y-solo/

Educarchile. (s.f.). Obtenido de https://www.educarchile.cl/john-dewey

Fallahy, C. (2011). Usando la taxonomía de Fink para el diseño de cursos, en Observer, vol. 24(7), 171-175.

Freire, P. (1968). Pedagogía del Oprimido. Verlag Herder.

Guiadeldocente. (Septiembre de 2019). Obtenido de https:/guiadeldocente.mx/que-es-lataxonomia-de-bloom-una-definicion-para-maestros/

Ministerio de Educación. (2015). Bases Curriculares $7^{\mathfrak{0}}$ básico a $2^{\underline{0}}$ medio. Santiago, Chile.

Ministerio de Educación. (1 de Abril de 2016). leychile. Obtenido de https://www.leychile.cl/Navegar?idNorma=1087343

Ministerio de Educación. (2019). Bases curriculares $3^{\circ}$ y $4^{\circ}$ Medio. Santiago, Chile.

Ministerio de Eduación (s.f.). curriculum nacional. Obtenido de https://curriculumnacional.mineduc.cl/614/articles-177739_archivo_01.pdf

Aiteco consultores desarrollo y gestión. (s.f.). Obtenido de https://www.aiteco.com/taxonomiade-bloom-y-objetivos-de-aprendizaje/

Martínez Silva, M. (Julio de 2003). Concepciones sobre la enseñanza de la resta: un estudio en el ambito de la formación permanente del profesorado. Barcelona.

Medina Dugarte, A. (s.f.). Taxonomía educativa integradora como estrategia didáctica para la planificación instruccional. Carabobo.

Mineduc. (2020). Texto del estudiante Lengua y literatura. Santiago: SM.

Moral Santaella, C. d. (2012). Conocimiento didáctico general para el diseño y desarrollo de experiencias de aprendizaje significativas en la formación del profesorado. Profesorada, 452 .

Olivera, S. W. (s.f.). Taxonomía de Bloom. Lima.

118 | INTEREDU № 1 VOL. I (DiciEMBRe 2019) PÁGs. 95-119. ISSN 2735-6523 
Pardo, R. (s.f.). Tecnologías Educativas más allá de las plataformas. Tecnologías Educativas más allá de las plataformas. Chile. Obtenido de http://observatorio.duoc.cl/sites/default/files/douc_2015.pdf

Pavié, A. (2014). Formación de profesores en Chile: modelos de formación inicial docente. Revista Inclusiones, 65-70.

Rodriguez Puerta, A. (s.f.). lifeder. Obtenido de https://www.lifeder.com/taxonomiamarzano/

Vélez, L. V. (2009). La investigación cualitaiva.

Vergara, J. R. (s.f.). Taxonomía Bloom-Anderson. 